\title{
STUDY ON SIGNAL INDUCED EXPRESSION OF COLD TOLERANCE IN EDIBLE LILY IN ALPINE ENVIRONMENT
}

\author{
TIAN, X. H. $.^{12^{*}}-$ XIE, J. M. ${ }^{2}-$ YU, J. H. ${ }^{2}$ \\ ${ }^{1}$ Department of Ecological and Environmental Engineering, Yangling Vocational \& Technical \\ College, Yangling 712100, China \\ ${ }^{2}$ College of Horticulture, Gansu Agricultural University, Lanzhou 730070, China \\ *Corresponding author \\ e-mail:txh_1214@126.com \\ (Received $3^{\text {rd }}$ Sep 2019; accepted $12^{\text {th }}$ Feb 2020)
}

\begin{abstract}
The objective of this experiment was to study the differentially expressed proteins and genes of edible lily in alpine environment, and to provide a better growth environment for edible lily. The edible lily of Heilongjiang Province, China, was selected as the object of the study. The samples were divided into two groups. The first group grew normally in the artificial climate box; the second group was treated at $4^{\circ} \mathrm{C}$ for 16 hours after spraying with Abscisic Acid (ABA) hormone, and the second group included edible lily No. 1 and edible lily No. 2. The total protein of one leaf was extracted by the trichloroacetic acid-acetone method and the differential protein spots of edible lily were analyzed by DeCyder software. The leaf genes of two edible lilies were extracted based on cold-resistant gene primer design. The results showed that alpine environments could induce energy metabolism, fatty acid metabolism, photosynthesis and signal transduction of differential proteins in edible lily; exogenous ABA could promote Coscisic Rirna (COR) gene expression by activating transcription factors dependent on ABA signaling pathway, and to some extent, it promotes the expression of cold resistance genes in signal pathways independent of $\mathrm{ABA}$, and improves the cold resistance of edible lily.
\end{abstract}

Keywords: differentially expressed proteins and genes, Abscisic Acid, cold-resistant gene primer design, energy metabolism, fatty acid metabolism

\section{Introduction}

Alpine environment is one of the main stress factors for lily growth processes. Alpine environment seriously damages Lily growth, even causing physiological imbalance of the whole lily, and bringing serious losses to production and ornamentation (Wei et al., 2017). Edible lilies are mainly distributed in the north temperate zone, the lowest temperature in winter can reach $-35^{\circ} \mathrm{C}$, but edible lilies can spend winter open field, adapt to the cold environment and continue to germinate and blossom in the next spring (Lu et al., 2017). In addition, they also have the ability to resist high temperature, drought and change soil salinity. However, with the deterioration of the ecological environment, the number of edible lilies has gradually decreased in recent years. Therefore, it is necessary to further protect the edible lily resources and explore the signal-induced expression of cold tolerance of Edible Lily in alpine environment. At present, there are many studies on Lily growth and yield in China. The results show that temperature and drought are the ecological factors restricting Lily regional distribution, abiotic stress directly affects Lily growth and development and yield, and even causes physiological imbalance of lily, which is the main reason for reducing Lily ornamental value (Templ et al., 2017).

The objective of this experiment was to study the differentially expressed proteins and genes of Edible Lily in alpine environment, and to provide a better growth environment for edible lily. In this paper, the differential protein analysis of edible lily and the effect of 
exogenous Abscisic Acid (ABA) on cold resistance gene expression in alpine environment were used to study the differential protein and gene expression of edible lily induced by two cold tolerance signals. ABA is a signal factor of plants responding to external stresses. The content of endogenous ABA increases significantly during cold acclimation, indicating that external cold stress increases ABA levels in plants and ABA is involved in signal transduction. With the development of signal transduction pathway research, ABA has become a research hotspot. It can induce related genes in stress response, and make them up-regulated or down-regulated. The ecological balance and metabolic activity of lily were affected by external stress. The expression of differentially expressed genes and the changes of differentially expressed proteins indirectly reflected the physiological activities of lily during the same period. Lily resumed normal metabolism through self-repair and regulation. Therefore, the study of proteomics will further explore the signal transduction pathway of Lily in response to external stress. Edible lilies live in a low temperature environment. In order to adapt to cold conditions, the protein and gene expression in Lily cells will change in response to cold stress. Lily was induced by cold stress and ABA hormone. The differential proteins were identified and classified by protein spectrum identification technology. The effect of ABA on the regulation process of cold-resistant genes of edible lily under cold stress was clarified. The relationship between the changes of protein points in Lily and the adaptation of cold and low temperature environment was discussed. Inverse mechanism and further scientific basis were provided to complete the signal-induced expression of cold tolerance of Edible Lily in alpine environment.

\section{Materials and methods}

\section{Materials}

Lily was selected from Heilongjiang Province of China for food (the same bulb should be propagated with the same genotype). Sample treatment was divided into two groups: $\mathrm{CK} 0 \mathrm{~h}$, i.e. the control plant grew normally in the artificial climate box; ABA + coldtreated $16 \mathrm{~h}$, i.e. the lily was treated at $4^{\circ} \mathrm{C}$ for $16 \mathrm{~h}$ after spraying ABA hormone. Sample 1 contained two kinds of Lily cultivars, edible lily 1 (10 lily leaves) and edible lily 2 (10 lily leaves), respectively. Sample 2 contained two kinds of Lily cultivars, edible lily 1 (10 lily leaves) and edible lily 2 (10 lily leaves). The mean minimum temperatures of two kinds of edible lilies collected in No. 2 Middle School were $4{ }^{\circ} \mathrm{C}, 0^{\circ} \mathrm{C},-10^{\circ} \mathrm{C}$ and $-25^{\circ} \mathrm{C}$, respectively. When sampling, 50 lilies with the same growth were randomly selected, washed with distilled water, dried and cut into $0.5 \mathrm{~cm}$ segments. After mixing, the leaves were frozen in liquid nitrogen and stored in a refrigerator at $-80^{\circ} \mathrm{C}$. Then the edible lily leaves of Sample 1 were taken to extract protein. The leaves of Edible Lily in Sample 2 were taken to extract genes.

\section{Main instruments for testing}

The test instruments include: GE Amersham (USA), Second-dimension: Hofer SE600 (GE Amersham), Scanner: UMaxPowerlook 21 IOXL (GE Amersham). Leica DFC500 stereo microscope, BIO-RAD UV Gel imaging system, BIO-RAD SmartSpec Plus UV spectrophotometer, BeckMan Coulter Allegra 648 centrifuge, Illumina company's Solexa genome analyzer (Allegra), fluorescence quantitative analyzer, sterilizing pot, 54158 centrifuge, G-storm-482 PCR, TaiSite water bath pot, Microwave oven (Figure 1). 


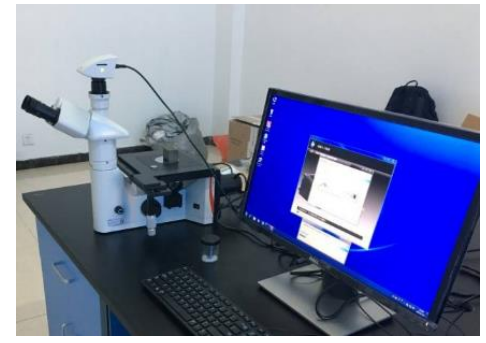

(a) Microscope

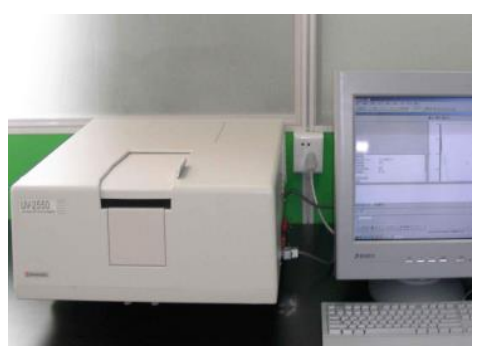

(b)Spectrophotometer

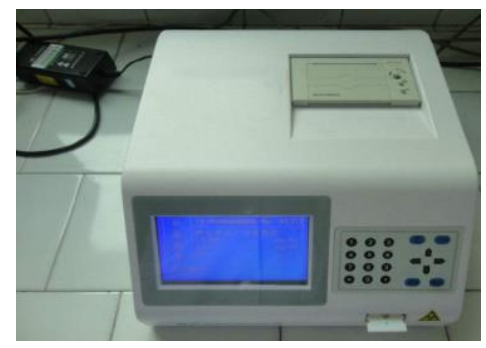

(c)Fluorescence quantitative analyzer

Figure 1. Main instruments for testing

\section{Test reagent}

The main reagents were solid phase $\mathrm{pH}$ gradient (IPG) tape $(24 \mathrm{~cm}, \mathrm{pH} 3-11)$, IPG buffer $\mathrm{pH} 3-11$, and ammonium bicarbonate was purchased from Sigma Company. CHCA (Sigma No. 034K3707), Merck No. 1499230-935, Merck No. 56002262-009, Mass Standards Kit for the 4700 Proteomics Analyzer (AB SCIEX No. 4333604), concentrated sulfuric acid, onion ketone, acetic acid, acetic acid, beta-sparse ethanol, EASYspinPplant RNA rapid extraction kit of Adelai Company (RLT, RLT Plus, RW1, RW, RNase-free H20, PLANTaid, Genomic DNA Clearance Column and Collection Tube, RNase-free Adsorption Column and Collection Tube), Promega'sPolyATtract RNA Isolation System III with mAGnetic Stand BioTinyLated-Oligo (dT), 20×SSC MMLV RTase Gene Synthesis Kit $(5 \times 1$ st strand synthesis Buffers $5 \times 2$ st strand synthesis Buffer, dNTP Mixtures RNase Inhibitor Oligo (DT), Reverse Transcriptase (M-MLV) (200 U/mL), EcoDNA Polymerase I, E. DNA Li Gase Mixture, T4 DNA Polymerase, Tris-HCL (pH 7.6), MgCL2, DTT, ATP, T4 DNA Ligase, EDTA, SDS, phenol/chloroform/isoamyl alcohol (25:24::1).

\section{Method}

The study was conducted on edible lilies in the alpine environment. The main picking site is Gansu Province in China, located between $32^{\circ} 11^{\prime}-42^{\circ} 57^{\prime}$ north latitude and $92^{\circ} 13^{\prime}-108^{\circ} 46^{\prime}$ east longitude. The terrain of Gansu is narrow and long, and the landforms are complex and diverse. The mountains, plateaus, Pingchuan, river valleys, deserts, and Gobi are surrounded by mountains and mountains. The terrain slopes from southwest to northeast. Gansu is located at the intersection of the three plateaus of the Loess Plateau, the Qinghai-Tibet Plateau and the Inner Mongolia Plateau. The annual average temperature is $0-15^{\circ} \mathrm{C}$. Taking edible lily in this area as a research example, the induced expression of lily cold tolerance signal in alpine environment was studied.

\section{Extraction of total protein from edible lily leaves}

Lily protein was extracted by trichloroacetic acid-acetone method (Shimo et al., 2017).

(1) Take a sample of about $1 \mathrm{~g}$ tissue, grind it with liquid nitrogen, add $45 \mathrm{~mL}$ TCA/acetone solution, stay overnight at $-20^{\circ} \mathrm{C}$, and centrifuge for 30 minutes to remove the supernatant.

(2) Add equal volume precooling acetone, centrifuge to remove supernatant, repeat this step until acetone is completely colorless; dry and precipitate at room temperature. 
(3) $1.5 \mathrm{~mL} 2 \mathrm{D}$ pyrolysis solution was added to the dry powder of each group, and the supernatant was obtained by ice-bath ultrasonic cooling treatment $(100 \mathrm{~W}, 10 \mathrm{~s}, 15 \mathrm{~s}$ interval, 10 times); $12000 \mathrm{rpm}, 4^{\circ} \mathrm{C}, 30 \mathrm{~min}$.

(4) Quantitative: Bio-Rad protein assay reagent was used to quantify and stored at $-80^{\circ} \mathrm{C}$.

\section{Identification of differentially expressed proteins in Edible Lily}

The differential protein spots of edible lily (Liu et al., 2017) were analyzed by DeCyder software. The original mass spectrometry documents were retrieved by in-gel enzymatic hydrolysis, Ziptip desalination, mass spectrometry analysis and Mascot 2.2 software. The identified protein results (Donaldson et al., 2017) were obtained.

\section{Primer design of cold resistance gene}

Based on the existing data of DFCI Wheat Gene Index and NCBI, the primers with good performance (Ahmed et al., 2019) were designed using the conserved regions of each coding enzyme and cold-resistant gene as templates. Primers should be designed strictly according to the requirement of real-time quantitative reaction in order to obtain primers with high amplification efficiency and specificity. The primers of cold-resistant genes were designed according to the requirements of fluorescence quantitative PCR, as shown in Table 1.

Table 1. Real-time quantitative PCR primers

\begin{tabular}{|c|c|c|c|}
\hline Gene & NCBI accession number & Primer type & Primer sequence 5, to 3, \\
\hline CBFII-5.2 & EF028753.1 & Forward & AACATCACCTCACTCACCAGTCA \\
\hline & & Reverse & GTACTGGTCCATGGTGTTGCA \\
\hline Wcor 15 & AB095006.1 & Forward & ACGACGCTGCGGATGCTAC \\
\hline & & Reverse & \\
\hline WCS120 & M93342.2 & $\begin{array}{l}\text { Forward } \\
\text { Reverse }\end{array}$ & \\
\hline & & Forward & ATGCACACACTGGAATGACC \\
\hline COR39 & AFO58794.1 & Reverse & GTGCTGTCCAGGCAGCTT \\
\hline CREIVd_D22 & FF028753 & Forward & GAGCCAGAGCCACTTGTTCA \\
\hline CDFIVU-DLZ & БГО20/J3.1 & Reverse & ACAAGATGCTACTGTGTTTCTCTCCAA \\
\hline MYB80 & AY625680 & Forward & CAGATAGAGCAACACCTAA \\
\hline 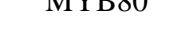 & AY 025080 & Reverse & AGAATGAATCACTAGAATCCT \\
\hline Wabi5 & AB193553.1 & Forward & GCAGGCTTATACAATGGA \\
\hline wabis & АВ 193553.1 & Reverse & GAACTGATCCTTCATCTCA \\
\hline Wrabl7 & AF255053 & Forward & TTTTACGGCGACAAGACTGAC \\
\hline Wrabl/ & AF 255053 & Reverse & GGGGTATCCTTGGTGTACTGTG \\
\hline
\end{tabular}

\section{Results}

\section{Extraction and quantification of protein from Edible Lily leaves}

Using 2-D quant Kit to quantify the total protein of Sample 1 and accurately quantify the lily protein is the precondition for the follow-up study of differential proteome. SDS-PAGE single-dimensional electrophoresis was used to further verify the quantitative results. Quant Tool software analysis and visual observation showed that the results of protein display were more accurate, indicating that the quantitative results of these proteins can continue to be used in the follow-up study of differential proteins. The results of protein quantification are shown in Table 2. 
Table 2. Quantitative results of protein

\begin{tabular}{c|c|c}
\hline Sample & Concentration $\boldsymbol{\mu g} / \boldsymbol{\mu} \mathbf{L}$ & Total $/ \boldsymbol{\mu} \mathbf{L}$ \\
\hline Sample 1 & 5.9 & 405 \\
Sample 2 & 5.9 & 705 \\
\hline
\end{tabular}

\section{Identification of differentially expressed protein profiles in Edible Lily}

In this study, 21 protein spots were selected and identified by MALDI-TOF mass spectrometry after two-dimensional electrophoresis analysis using imageMaster 2D Elite Platnum software. Finally, 20 proteins were obtained complete peptide fingerprints, and 19 proteins were successfully identified by searching MIPS database. The identification results are shown in Table 3.

Table 3. Identification of Protein Points in Edible Lily Leaves under Low Temperature Stress by Mass Spectrometry

\begin{tabular}{|c|c|c|c|c|c|}
\hline Number & Protein Identification & Organism & Biologi & \begin{tabular}{|c|} 
Protein \\
Score \\
\end{tabular} & PI/MW \\
\hline $\mathrm{J} 24$ & $\begin{array}{l}\text { Late embryogenesis } \\
\text { abundant protein }\end{array}$ & VitisVinifera & $\begin{array}{l}\text { Response to abiotic } \\
\text { Transport; signal tr: }\end{array}$ & 66 & $39220 / 5.14$ \\
\hline K1 & $\begin{array}{l}\text { Photosystem I reaction } \\
\text { center subunit II } \\
\text { chloroplastic-like }\end{array}$ & Setar & $\begin{array}{l}\text { Protein metabolic pro } \\
\text { cycle; Generation of } \\
\text { metabolites and e }\end{array}$ & 296 & 10.04 \\
\hline K2 & $\begin{array}{c}\text { Integrasetransposasefamily } \\
\text { protein }\end{array}$ & Halorubrmalam & $\begin{array}{l}\text { Response to abiotics } \\
\text { transport; signal tran }\end{array}$ & 71 & $22788.4 / 5.23$ \\
\hline K3 & $\begin{array}{r}\text { Cytochrom } \\
\text { iron-su }\end{array}$ & Zea mays & $\begin{array}{r}\text { Generation of } \\
\text { and energy; }\end{array}$ & 214 & $24321.3 / 8.52$ \\
\hline K4 & $\begin{array}{r}\text { Intracellul } \\
\text { related } \mathrm{p}\end{array}$ & Liliumlongiflorum & $\begin{array}{l}\text { Response } \\
\text { transcripna }\end{array}$ & 97 & $16699.6 / 5.37$ \\
\hline K5 & $\begin{array}{r}\text { ATP depe } \\
\text { hel }\end{array}$ & Chondruscrispus & $\begin{array}{r}\text { Response t } \\
\text { abiotic }\end{array}$ & 62 & $83477.9 / 8.9$ \\
\hline K6 & $\begin{array}{l}\text { Ribulose-1, 5-bisphosp } \\
\text { hatecarboxylase / } \\
\text { oxygenaselarge subunit }\end{array}$ & Dioscoreaschimperiana & $\begin{array}{r}\text { Biosynthetic prc } \\
\text { hydrate metabolism } \\
\text { metabolic }\end{array}$ & 437 & $51125.6 / 6.44$ \\
\hline K7 & Zinc finger protein 51 & Musmusculus & Metablicprocess; cellular process & 69 & $86746.1 / 9.07$ \\
\hline K8 & $\begin{array}{c}\text { Phosphoglycerate mutase } \\
\text { 2, 3-bisphosphoglycerate- } \\
\text { independent isoform }\end{array}$ & Theobroma cacao & $\begin{array}{c}\text { Response to stress; biological } \\
\text { process; carbonhydrate metablic } \\
\text { process; catabolic process; } \\
\text { Generation of precursor metabolites } \\
\text { and energy }\end{array}$ & 256 & $48133.4 / 5.9$ \\
\hline K9 & $\begin{array}{l}\text { UPF0664 stress-induced } \\
\text { protein C29B12. 11c-like }\end{array}$ & Brachypodiumdistachyon & $\begin{array}{l}\text { Response to stress; respor } \\
\text { abiotic stimulus; transp }\end{array}$ & 83 & $22956.4 / 7.01$ \\
\hline K10 & Aconitatehydratase & pinus & Response to stress & 213 & $40867.6 / 6.34$ \\
\hline K11 & $\begin{array}{r}\text { S-adenosy } \\
\text { synt }\end{array}$ & Populustrichocarpa & $\begin{array}{c}\text { Generation of precursor metabolites } \\
\text { and energy }\end{array}$ & 546 & $43564.9 / 5.5$ \\
\hline K12 & Kerat & Hom & $\begin{array}{c}\text { Generation of precursor metabolites } \\
\text { and energy }\end{array}$ & 277 & $66184.1 / 8.15$ \\
\hline K13 & Protei & Cryptobacte & $\begin{array}{r}\text { Carbonhy } \\
\mathrm{ca}\end{array}$ & 75 & $105722.9 / 5.07$ \\
\hline K14 & $\begin{array}{l}\text { Receptor-like protein } \\
\text { kinase }\end{array}$ & Ricinuscommunis & $\begin{aligned} \text { Resp } \\
\text { tra }\end{aligned}$ & 275 & $21732.9 / 6.1$ \\
\hline K15 & $\begin{array}{l}\text { Cytosolic malate } \\
\text { dehydrogenase }\end{array}$ & Sugarcane mosaic virus & $\begin{array}{l}\text { Carl } \\
\text { cata }\end{array}$ & 117 & $39790.3 / 5.7$ \\
\hline K17 & Actin & Liliun & $\begin{array}{l}\text { Response to stress; Transcription; } \\
\text { transport; signal transduction }\end{array}$ & 147 & $41847.1 / 5.31$ \\
\hline K18 & $\begin{array}{l}\text { Oxygen- } \\
\text { prote }\end{array}$ & Arabidopsis thaliana & $\begin{array}{r}\text { Generation of } p \\
\text { and energy }\end{array}$ & 96 & $28231.3 / 8.67$ \\
\hline K19 & $\begin{array}{c}\text { Conjugal transfer protein } \\
\text { Tral }\end{array}$ & Escherichia coli & $\begin{array}{l}\text { Transcription; transport; signal; } \\
\text { transduction }\end{array}$ & 80 & $188993.2 / 5.78$ \\
\hline 20 & $\begin{array}{l}\text { peptide 1-prolylcis-trans } \\
\text { isomerase FKBP5-like }\end{array}$ & Oreochromisniloticus & $\begin{array}{l}\text { response to stress; Transcription; } \\
\text { transport; signal transduction }\end{array}$ & 66 & $52267.3 / 8.69$ \\
\hline
\end{tabular}




\section{Functional analysis of differentially expressed proteins in edible lily under different treatment conditions}

Table 3 shows that a protein can participate in different biological processes and play different roles in response to external stresses. Four differentially expressed proteins are stress response related proteins. Three proteins are involved in signal transduction, four proteins are related to energy metabolism, three proteins are related to photosynthesis response, and the other three proteins may be involved in other biological processes. In this study, stress response related proteins, signal transduction proteins and energy metabolism proteins were introduced in detail.

\section{Changes in expression of stress-related proteins}

Four differentially expressed proteins are stress response-related proteins, namely J24:LEA synthetic protein; K2:transcriptase family protein; K9:stress-induced protein. The expression of PR-107 was significantly down-regulated, while the expression of other proteins was significantly up-regulated. Protein Point K4: Some results of mass spectrometry identification of cell disease resistance protein PR-107 are shown in Figure 2.

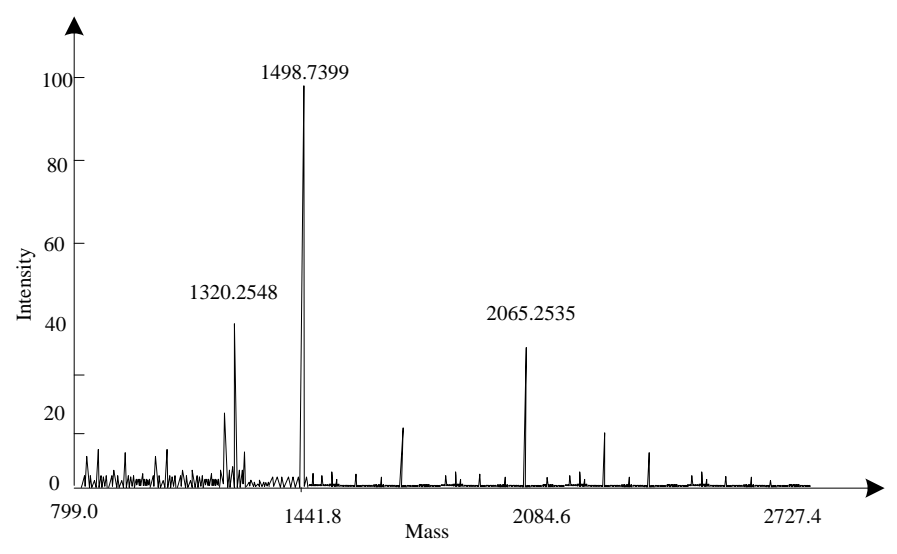

Figure 2. Protein point $K 4$ mass spectrometry identification partial results

\section{Participation in signal transduction proteins}

In this study, three signal transduction related proteins were identified, namely K14: receptor protein kinase; K19: combined transporter; K20: peptide-prolylcis-trans isomerase. The expression of K14 and K19 protein was significantly up-regulated, but the abundance of the peptide-prolylcis-trans isomerase $\mathrm{K} 20$, which played a role in protein folding, was down-regulated under low temperature stress. K14: Some of the results of mass spectrometric identification of receptor protein kinases are shown in Figure 3.

\section{Proteins involved in energy metabolism}

In this study, four differentially expressed proteins, K5:ATP synthase; K6:ribose-1,5diphosphate carboxylase/oxygenase subunit; K8:2,3-diphosphate glycerol mutase, were identified under the regulation of low temperature stress. The expression abundance of these three proteins was more than two times under cold stress and increased 
significantly. K15 is malic deoxygenase, and its expression is significantly up-regulated. K6: Some results of the identification of ribose-1,5-diphosphate carboxylase / oxygenasemacrosubstrates are shown in Figure 4.

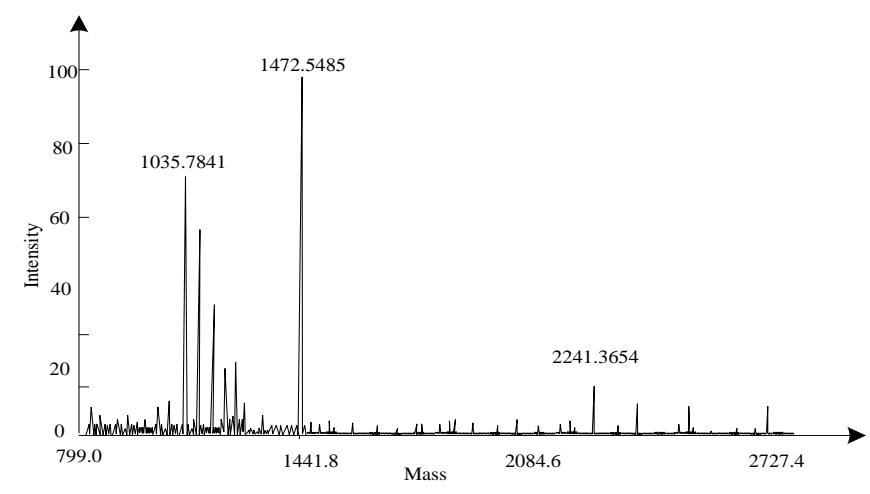

Figure 3. Partial results of protein point K14 mass spectrometry identification

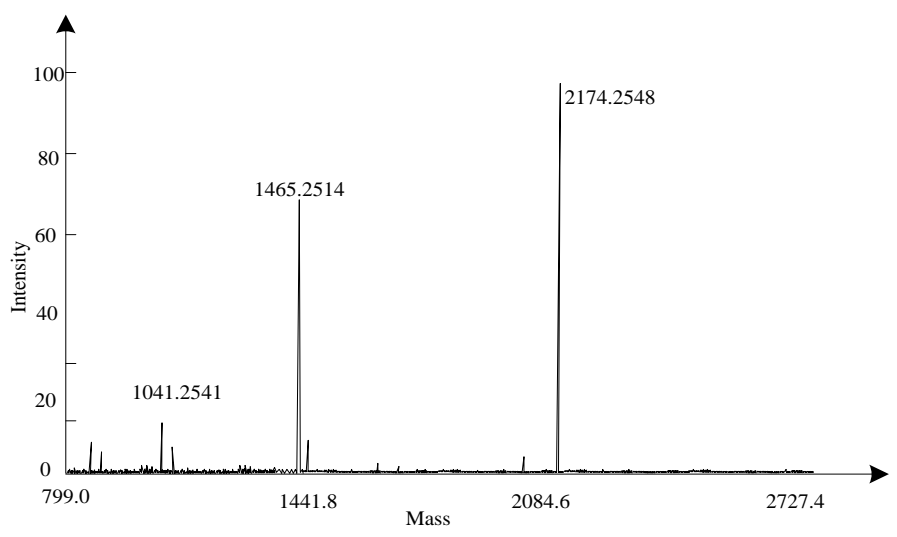

Figure 4. Protein point K6 mass spectrometry identification partial results

\section{Effect of exogenous ABA on cold-resistant gene expression of Edible Lily in alpine environment}

Effects of exogenous $A B A$ on the expression of $C B F$ and COR genes independent of $A B A$ in edible lily under high and cold environment

The expression of TaCBFII-5.2 gene in leaf control group of two edible lily cultivars increased first and then decreased. The expression of TaCBFII-5.2 gene in leaf control group of edible lily cultivar No. 2 increased again at $-25^{\circ} \mathrm{C}$. The peak values above $0^{\circ} \mathrm{C}$ were shown in Figure $5 a$ and Figure $5 b$. Exogenous ABA treatment promoted the expression of TaCBFII-5.2 gene in the leaves of edible lily No. 1 and reached a significant level at temperatures above $0^{\circ} \mathrm{C}(\mathrm{P}<0.05)$; in the leaves of edible lily No. 2 , the expression of TaCBFII-5.2 gene in the ABA treatment group was higher than that in the control at $4^{\circ} \mathrm{C}$, and reached a significant level $(\mathrm{P}<0.05)$, but at temperatures below $0^{\circ} \mathrm{C}$ and below. The expression of the gene in the ABA treatment group was lower than that in the control group, and the difference reached significant level at $0^{\circ} \mathrm{C}$ and $-25^{\circ} \mathrm{C}(\mathrm{P}$ $<0.05)$. 

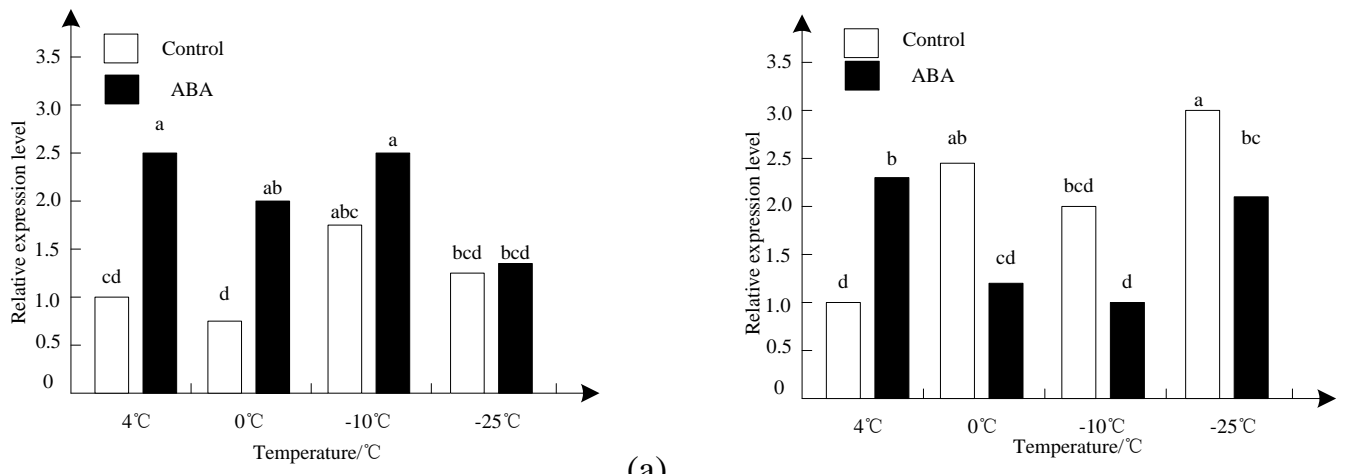

(a)
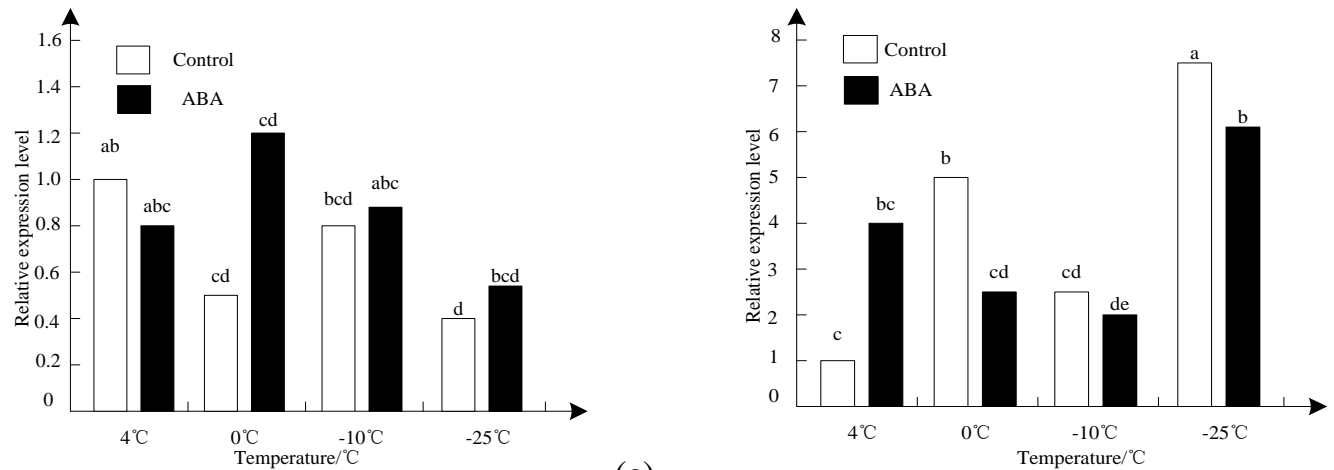

(c)
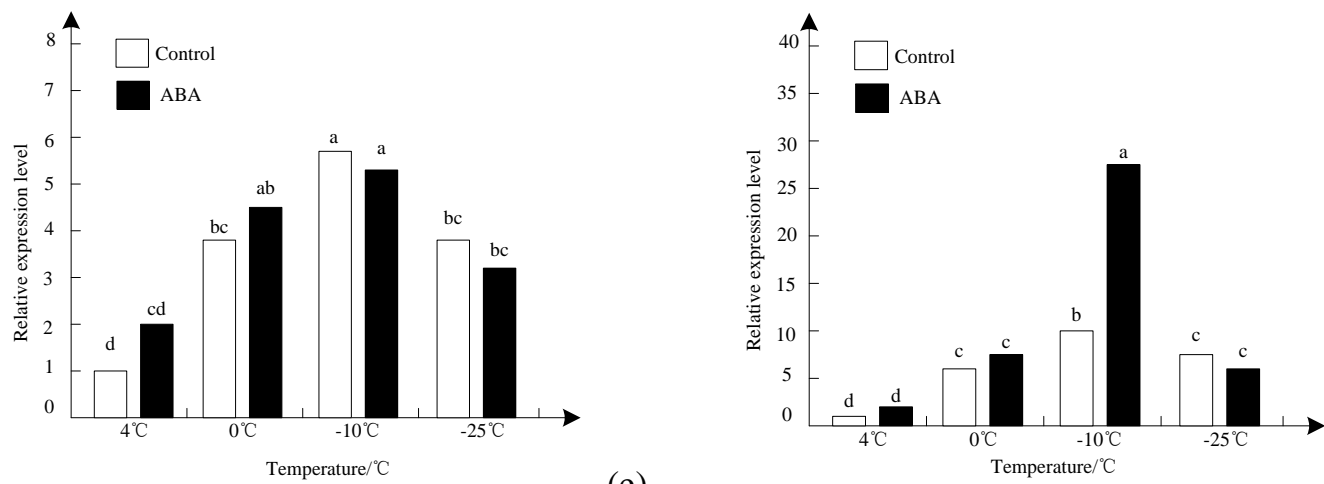

(e)
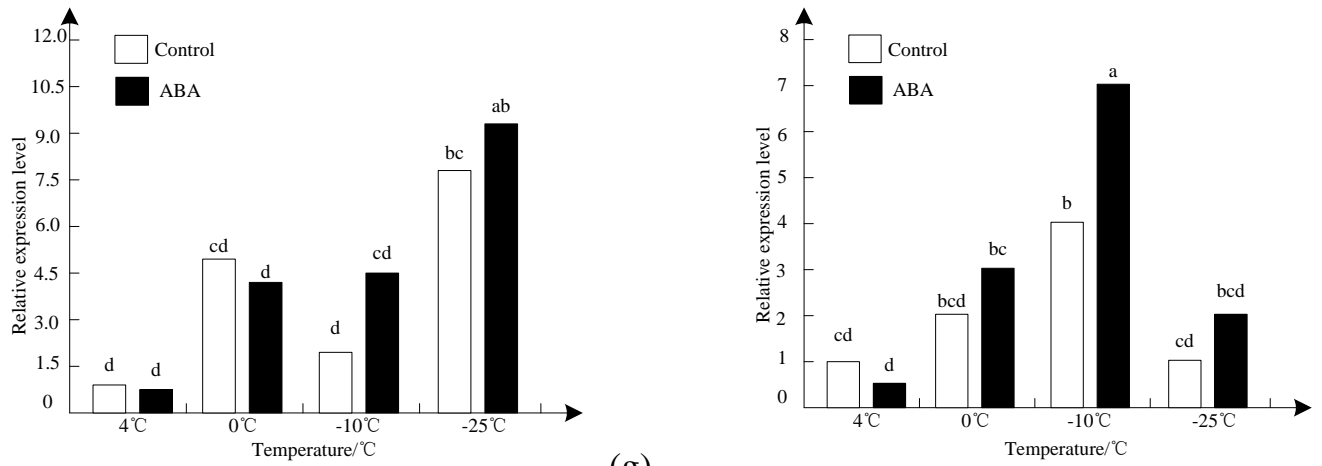

(g)

(h)

Figure 5. Relative expressions of TaCBFII-5.2, TaWcorl5, TaWcs 120 and TaCOR39 in leaves of two edible lilies at low temperature during winter. There were significant differences in different letters of edible lily of the same cultivar ( $p<0.05$ ); TaCBFII-5.2, TaWcorl 5, TaWcs 120, TaCOR39 genes of edible lily No. 1 leaves were a, $c$, e and $g$ respectively, and TaCBFII-5.2, TaWcorl 5, TaWcs 120 and TaCOR39 genes of edible lily No. 2 leaves were b, $d, f$ and $h$, respectively 
The expression of TaWcorl15 gene in the leaf control group of edible lily No. 1 showed a downward and downward trend. As shown in Figure $5 c$, the expression of TaWcorl5 gene was inhibited by exogenous ABA at the initial stage of low temperature at $4^{\circ} \mathrm{C}$, but the expression of TaWcorl5 gene was promoted after the temperature continued to decrease, but the difference was not significant. The expression of TaWcorl5 gene in the leaves of control group No. 3 showed a rising and falling trend. As shown in Figure $5 d$, exogenous ABA only promoted the expression of TaWcorl5 gene at $4^{\circ} \mathrm{C}(<0.05)$ in the early stage of low temperature, but inhibited the expression of TaWcorl5 gene at other temperatures, and reached a significant level at $0^{\circ} \mathrm{C}(<0.05)$ and $-25^{\circ} \mathrm{C}(<0.05)$.

The expression of TaWcs 120 gene in the leaves of two lily cultivars increased first and then decreased. As shown in Figure $5 e$ and Figure 5f, the expression of TaWcs 120 gene in the leaves of Lily cultivar No. 1 treated with ABA was higher than that in the control at temperatures above $0^{\circ} \mathrm{C}$, while the expression of TaWcs 120 gene was inhibited at temperatures below $0^{\circ} \mathrm{C}$, but the expression of TaWcs 120 gene was inhibited at temperatures below $0^{\circ} \mathrm{C}$. At all temperatures, there was no significant difference between the two treatments. The expression of TaWcs 120 gene in the leaves of Lily No. 2 treated with ABA was higher than that in the control group at temperatures above $-10^{\circ} \mathrm{C}$, and reached a significant level at $-10^{\circ} \mathrm{C}(\mathrm{P}<0.05)$. The expression of TaWcs 120 gene in the leaves of Lily No. 2 treated with ABA was lower than that in the control group at late $-25^{\circ} \mathrm{C}(\mathrm{P}<0.05)$, but the difference between the two treatments was not significant.

The expression of TaCOR39 gene in leaves of two edible lily control groups increased first and then decreased, as shown in Figure $5 \mathrm{~g}$ and Figure $5 \mathrm{~h}$. However, at the lowest temperature $-25^{\circ} \mathrm{C}$, the expression of the gene in the leaves of edible lily No. 1 increased to a peak. In the leaves of Lily cultivars, ABA inhibited the expression of TaCOR39 gene in the early stage of low temperature, and promoted the expression of TaCOR39 gene in the late stage of low temperature, but the difference between the two treatments was significant only at $-10^{\circ} \mathrm{C}(\mathrm{P}<0.05)$.

Effects of exogenous $A B A$ on the expression of $A B A$-dependent transcription factor genes and COR genes in edible lilies in alpine environment

TaCBFIVd-D22, TaMYB80 and TaWabi5 are ABA-dependent transcription factors.

The expression of TaCBFIVd-D22 gene in the leaves of the control group showed a downward and downward trend. As shown in Figure $6 a$, exogenous ABA significantly inhibited the expression of TaCBFIVd-D22 gene at the initial stage of low temperature $(\mathrm{P}<0.05)$, and increased the expression of TaCBFIVd-D22 gene at the lowest temperature, reaching a significant level at $0^{\circ} \mathrm{C}$ and $-10^{\circ} \mathrm{C}(<0.05)$. The expression of TaCBFIVd-D22 gene in the leaves of edible lily No. 2 increased as a whole. As shown in Figure 6b, exogenous ABA significantly promoted the expression of TaCBFIVd-D22 gene $(\mathrm{P}<0.05)$ in the early stage of low temperature at $4^{\circ} \mathrm{C}$, but inhibited the expression of TaCBFIVd-D22 gene when the temperature continued to decrease, reaching a significant level at 0 and $-25^{\circ} \mathrm{C}(\mathrm{P}<0.05)$.

The expression of TaMYB80 gene increased first and then decreased with the decrease of temperature in the control group. As shown in Figure $6 c$ and $6 d$, exogenous ABA treatment promoted the expression of TaMYB80 gene in the leaves of edible lily No. 1. The difference between the two treatments was significant at low temperatures $(\mathrm{P}<0.05)$. In edible lily No. 2 leaves, exogenous ABA significantly promoted the 
expression of TaMYB80 gene only at $4^{\circ} \mathrm{C}$ in the early stage of low temperature $(\mathrm{P}<0.05)$, and inhibited the expression of TaMYB80 gene at other temperatures, especially at $0^{\circ} \mathrm{C}$ and $-25^{\circ} \mathrm{C}$.

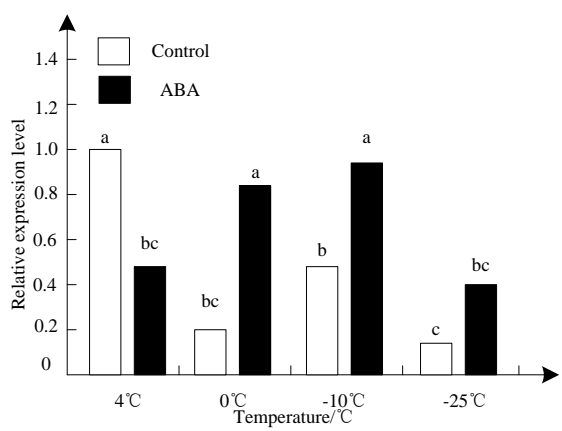

(a)
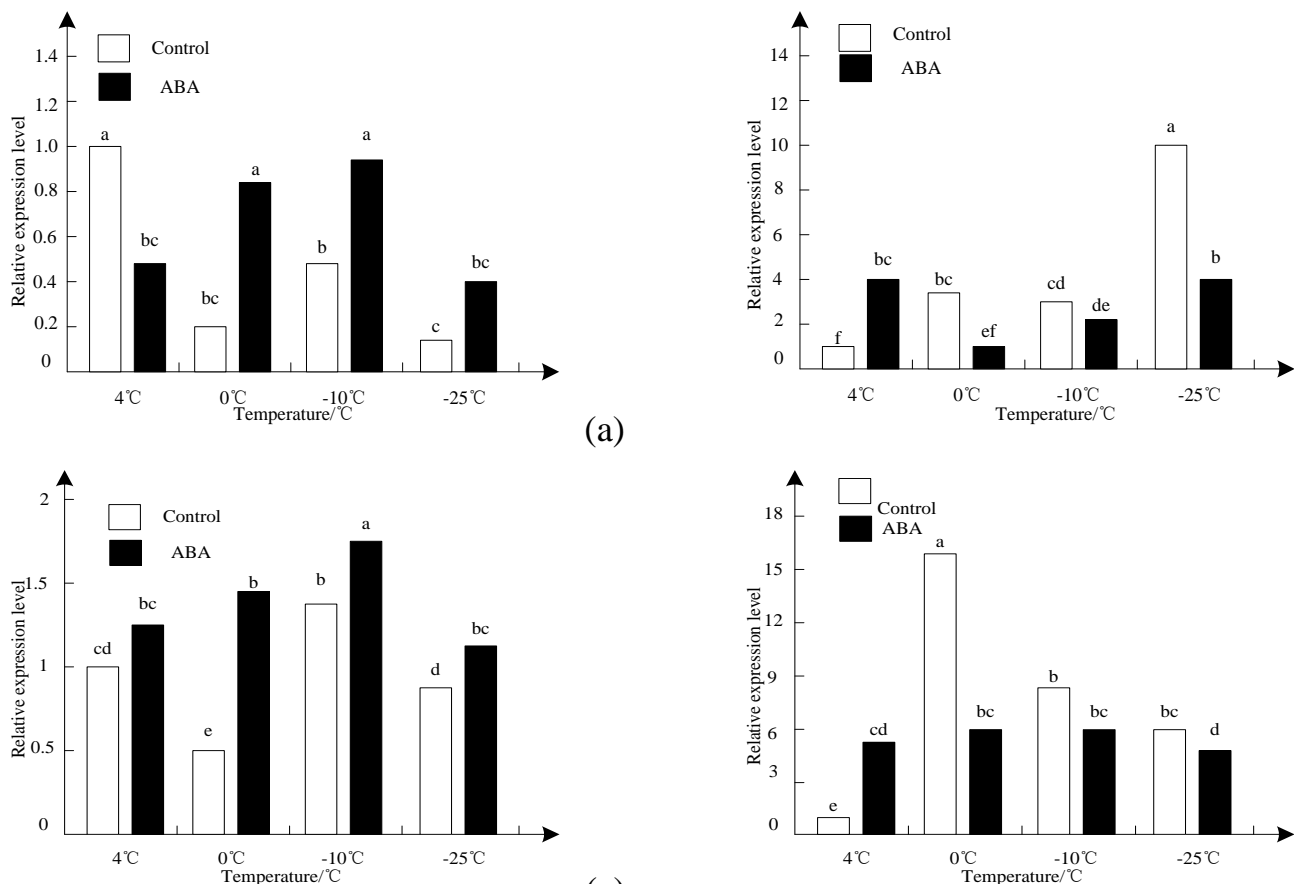

(b)

(c)

(d)
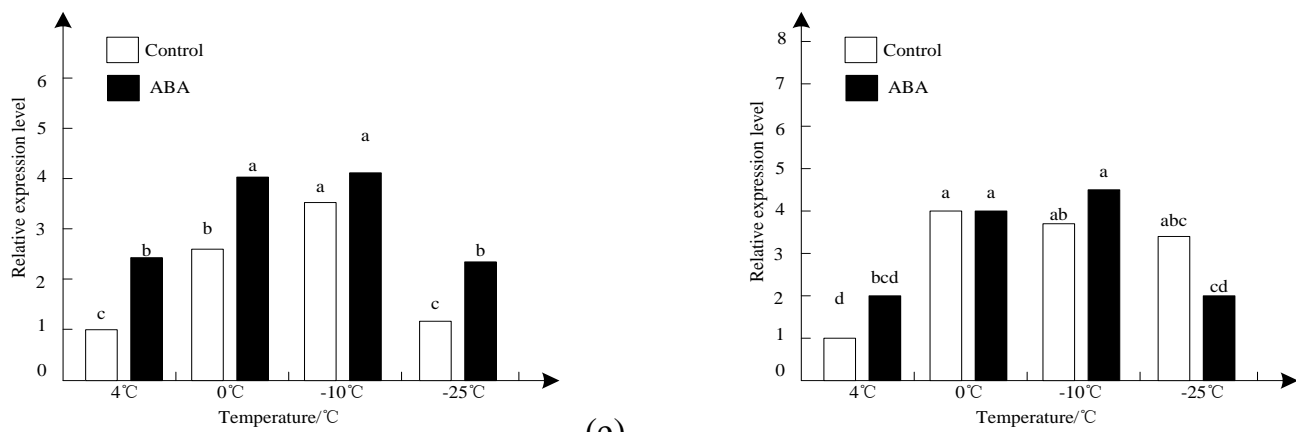

(e)

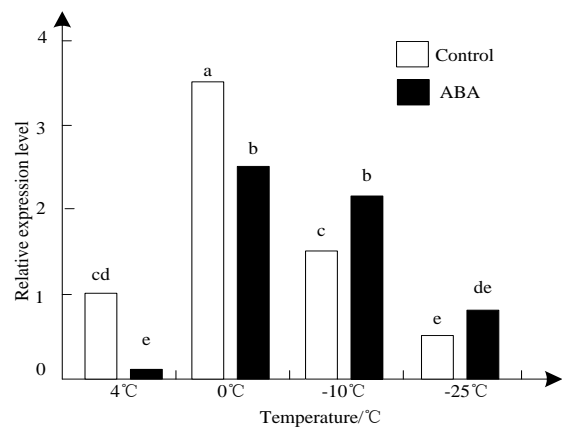

(f)

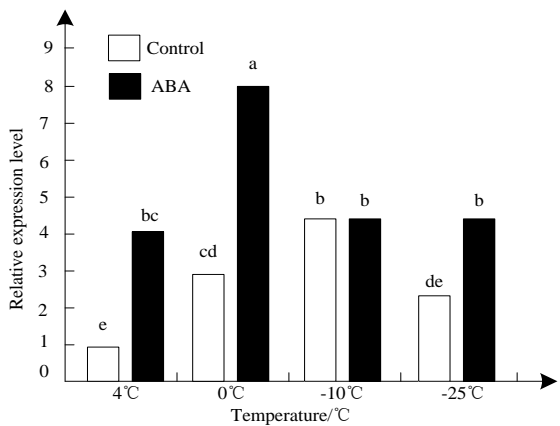

(g)

(h)

Figure 6. Relative expressions of TaCBFIVd-D22, TaMYB80, TaWabi5 and TaWrabl7 in leaves of two edible lilies during winter. There were significant differences in different letters of edible lily of the same variety ( $p<0.05$ ); TaCBF1Vd-D22, TaMYB80, TaWabi5 and TaWrabl7 genes of edible lily No. 1 leaf were TaCBF1Vd-D22, TaMYB80, TaWabi5 and TaWrabl7 genes respectively; and $b, d$, f and $h$ genes of edible lily No. 2 leaf were TaCBF1Vd-D22, TaMYB80, TaWabi5 and TaWra7 genes, respectively 
TaWabi5 belongs to the transcription factor of bZIP family. The expression of TaWabi5 gene in the leaves of two edible lily varieties increased first and then decreased. As shown in Figure $6 e$ and $6 f$, exogenous ABA treatment promoted the expression of TaWabi5 gene in the leaves of edible lily No. 1. Except $-10^{\circ} \mathrm{C}$, the difference reached significant level $(\mathrm{P}<0.05)$. In the leaves of edible lily No. 2 , the expression of TaWabi5 gene reached a significant level $(\mathrm{P}<0.05)$. Exogenous ABA promotes the expression of the gene at degree, but there is no significant difference between the two treatments, it inhibits the expression of the gene at the late stage of low temperature $-25^{\circ} \mathrm{C}$, and the difference is not significant.

TaWrabl7 belongs to ABA-dependent COR gene. The expression of TaWrabl7 gene in the leaves of two edible lilies increased first and then decreased, as shown in Figure $6 g$ and $6 h$. In edible lily No. 1 leaves, exogenous ABA promoted the expression of TaWrabl7 gene, reaching a significant level $(\mathrm{P}<0.05)$ except $-10^{\circ} \mathrm{C}$. In edible lily No. 2 leaves, exogenous ABA significantly inhibited the expression of TaWrabl7 gene at temperatures above $0^{\circ} \mathrm{C}$, while temperature continued to decrease, and then promoted its expression at $-10^{\circ} \mathrm{C}$. In edible lily No. 2 leaves, exogenous ABA significantly inhibited the expression of TaWrabl7 gene. The difference was significant $(\mathrm{P}<0.05)$.

\section{Discussions}

\section{Functional analysis of differential proteins}

Mass spectrometry analysis revealed that differential proteins were mainly involved in the balance of photosynthetic respiration, carbon, nitrogen, sulfur and energy metabolism, protein translation, protein processing, signal transduction, RNA processing and redox (Tang et al., 2017). In this study, differential proteomics of edible lily leaves under low temperature stress was studied. Twenty-one protein spots were selected and identified by MALDI-TOF mass spectrometry (Wu et al., 2018) after the analysis of protein spots with more than two-fold abundance in two-dimensional electrophoresis (2-DE) by using ImageMaster 2D Elite Platnum software. Finally, 20 proteins obtained complete skin fingerprints. These 19 proteins were successfully identified by searching the MIPS database. The identification results showed that they were involved in energy metabolism, fatty acid metabolism, photosynthesis and signal transduction. The possible physiological functions of these proteins in response to low temperature stress are discussed below.

\section{Stress-related proteins}

The Edible Lily will produce a series of proteins with protective function after being stressed by adversity. Late embryogenesis abundant proteins (LEA proteins) is one of the most important proteins (Li et al., 2017). LEA protein was first discovered in 1981. It can be enriched in the process of dehydration during the late stage of embryonic development and can improve the resistance of seeds to dehydration (He et al., 2019). Dehydration is a highly hydrophilic and molecular chaperone in the metabolic process of edible lily, which can stabilize the structure and properties of cell membranes, avoid protein denaturation caused by water shortage caused by low temperature stress, and reduce external damage to plants. A large number of studies have shown that cold stress can promote the accumulation of large amounts of LEA protein (Li et al., 2017) in plants. The expression level of LEA protein spots (J24) identified in this study was 
significantly up-regulated, indicating that LEA protein played an important role in the resistance of edible lily to external stresses and reduced the damage of edible lily plants under low temperature stress. K2: transcriptase family protein; K4: cell disease resistance protein PR-107; K9: stress-induced protein, the expression of cell disease resistance protein $(\mathrm{K} 4)$ was significantly down-regulated, and other protein expression was significantly up-regulated.

\section{Signal transduction related proteins}

When lily is stressed, plant cells receive signals, which are received by cell membrane sensors, and then transferred from cytoplasm to nucleus by a second signal molecule, such as catalytic protein kinase. In nucleus, protein kinase $\mathrm{C}$ and PPPC can induce $\mathrm{Ca}^{2+}$ and ABA pathways respectively to initiate signal transduction (Xu and $\mathrm{Zhu}$, 2017). After opening the defense mechanism, it mainly includes physical structural adaptation, such as changes in lipid composition and extracellular metabolic activities, increased intercellular osmotic protective agents such as soluble sugar, proline, betaine, etc., and up-regulated synthesized antioxidants such as superoxide dismutase, pathogen defense, catalase, ascorbic acid reductase, recovery. The balance of complex biosynthesis and carbohydrate metabolism can improve the survival rate of Edible Lily in cold environment. When most signaling molecules bind to their receptors, they begin to regulate cellular behavior, including intracellular responses to metabolism, exercise, proliferation, survival and differentiation. Finally, the edible lilies were adapted to cold acclimation and resisted external stress (Jiang et al., 2017). In this study, an up-regulated protein, receptor protein kinase (K14, RLK), was identified as a signal-accepting receptor protein with a single transmembrane alpha-helix receptor. When plants respond to low temperature stress, the expression of receptor protein kinase is significantly up-regulated. It is speculated that it may be stimulated by external cold signals and participate in the process of signal transduction in cell membranes and intracellular membranes. It can transmit signals to the nucleus and inspire the expression and regulation of downstream genes. It is a series of physiological and biochemical sounds produced by plants cold stress (Yu et al., 2017). Studies have shown that active protein molecules have specific amino acid sequences and threedimensional spatial structures, and the sequences of these genes are folded into proteins with specific structures and functions. The polypeptide prolinephthalidecis-trans isomerase CIS (K20) identified in this study has protein folding effect. It belongs to the chloroplast membrane protein, which can transmit cold signals in chloroplasts, and its expression changes directly lead to changes in the structure of chloroplast membrane.

\section{Energy metabolism related proteins}

Liu et al. (2017) showed in related research that proteins and enzymes play an important role in plant response to low temperature stress signal pathway, and the expression of genes related to these proteases are up-regulated or down-regulated. Proteins are involved in the primary and secondary metabolic processes of plants in response to stress, especially in osmotic regulators and soluble sugar soluble proteins (Liu et al., 2017). In plants, energy provides essential ATP for various life activities and intermediate metabolites for many metabolisms, so it is the basic metabolism of various life activities (Yu et al., 2018).

In this study, four differentially expressed proteins were identified, including protein points $\mathrm{K} 6, \mathrm{~K} 8$ and $\mathrm{K} 15$, which play an important role in the tricuspid acid cycle and 
participate in the glycolysis process of material and energy metabolism pathway. Protein point K5 is the key enzyme of oxidative phosphorylation. The increase of their expression level will promote the synthesis of downstream substances and provide essential substances and energy for edible lilies to cope with low temperature stress. At the same time, it can promote the changes of extracellular metabolic activities, restore the balance of biosynthesis and carbohydrate metabolism, and improve the survival rate in cold environment.

\section{Effect of exogenous $A B A$ on cold resistance gene expression}

Exogenous $\mathrm{ABA}$ can regulate the synthesis of endogenous ABA. ABA plays an important role in ABA-dependent signal transduction pathway. Many studies have shown that ABA may activate bZIP transcription factors and regulate COR genes that depend on ABA. The activation regions of these COR genes contain ABREs. Other transcription factors such as $\mathrm{MYC} / \mathrm{MYB}$ and $\mathrm{CBF} 4$ also play an important role in ABA-dependent stress signal transduction pathways (An et al., 2017). At present, many bZIP transcription factors, MYC/MYB transcription factor, $\mathrm{CBF} 4$ gene and ABA-dependent COR gene have been isolated and identified in Edible Lily and other plants. TaWabi5 gene is a bZIP transcription factor in edible lily, TaMYB80 is a MYC/MYB transcription factor in edible lily, TaCBF4 is an ABA-dependent CBF transcription factor in edible lily, and TaWrabl7 belongs to the ABA-dependent COR gene in Edible Lily (Chen et al., 2019). In this study, we found that exogenous ABA promoted the expression of TaCBF4 gene in leaves of edible lily No. 1 at the late stage of moderate and low temperatures, and exogenous ABA promoted the expression of TaMYB80, TaWabi5 and TaWrabl7 genes in leaves of edible lily No. 1, while exogenous ABA only promoted the expression of TaMYB80, TaWabi5 and TaWrabl7 genes in leaves of edible lily No. 2 at the early stage of low temperature at $0^{\circ} \mathrm{C}$ or above The expression of these cold-resistant genes was inhibited when the temperature was lowered.

In ABA-independent signaling pathways, low temperature can promote the expression of $\mathrm{CBF}$ family transcription factors, while $\mathrm{CBF}$ transcription factors may cause the expression of many downstream COR genes to improve plant cold resistance. TaCBFII-5.2 is a CBF/DREB transcription factor in edible lilies. This study found that in high-cold environment, at temperatures of $-10^{\circ} \mathrm{C}$ and above. Exogenous ABA promotes the expression of this gene (Lee et al., 2017). Exogenous ABA has no significant effect on the expression of COR gene independent of ABA in the leaves of two edible lilies.

\section{Conclusions}

In this paper, the differential protein of edible lily and the expression of coldresistant gene of exogenous ABA in alpine environment were studied. The research results are as follows:

Differential protein of edible lily showed that differentially expressed protein participated in many life processes such as acceptance and transmission of stress signals, promotion of substance and energy metabolism, regulation of photosynthesis and respiration, and improved the ability of edible lily to resist external stress.

Exogenous ABA may promote COR gene expression by activating transcription factors that depend on ABA signaling pathway, and improve cold resistance of edible 
lily. The results show that the effects of exogenous ABA on cold resistance genes in winter Edible Lily are inconsistent in alpine environment. The effect of exogenous ABA on cold resistance gene expression of edible lily may be enhanced by activating transcription factors that depend on ABA signaling pathway. The noise was more obvious in Edible Lily No. 1 than in Edible Lily No. 2. However, exogenous ABA also has some effects on cold-resistant genes in signal pathways independent of ABA, and can promote the expression of these genes to a certain extent. It can be seen that the effect of exogenous ABA on cold resistance gene expression of Edible Lily in high-cold environment is a complex process, and more mechanisms need to be further explored.

Acknowledgement. This work was supported by grants from the Key Research and Development Projects in China (No. 2016YFD0201005) and the Yang Ling College of Vocational Technology Natural Science Fund Project (No. A2017027).

\section{REFERENCES}

[1] Ahmed, B., Rizvi, A., Zaidi, A., Khana, M. S., Musarrat, J. (2019): Understanding the phyto-interaction of heavy metal oxide bulk and nanoparticles: evaluation of seed germination, growth, bioaccumulation, and metallothionein production. - RSC Advances 9(8): 4210-4225.

[2] An, D., Ma, Q., Wang, H., Yang, J., Zhou, W., Zhang, P. (2017): Cassava C-repeat binding factor 1 gene responds to low temperature and enhances cold tolerance when overexpressed in Arabidopsis and cassava. - Plant Molecular Biology 94(1): 109-124.

[3] Chen, X., Duan, X., Wang, S., Wu, W., Zhang, X. (2019): Virus-induced gene silencing (VIGS) for functional analysis of MYB80 gene involved in Solanum lycopersicum cold tolerance. - Protoplasma 256(2): 409-418.

[4] Donaldson, J., Madziva, M. T., Erlwanger, K. H. (2017): The effects of high-fat diets composed of different animal and vegetable fat sources on the health status and tissue lipid profiles of male, Japanese quail (Coturnix coturnix japonica). - Asian-Australasian Journal of Animal Sciences 30(5): 700-711.

[5] Jiang, R., Qi, L. D., Du, Y. Z., Li, Y. X. (2017): Thermotolerance and Heat-Shock Protein Gene Expression Patterns in Bemisia tabaci (Hemiptera: Aleyrodidae) Mediterranean in Relation to Developmental Stage. - Journal of Economic Entomology 110(5): 2190-2198.

[6] Li, R. Q., Yu, A., Bai, B., Xu, R., Ding, W. J. (2016): Potential Health and Ecological Risks of Accumulation of Cadmium, Lead and Mercury in Soil-Edible Lily Systems. Food Science 12(6): 52-60.

[7] Li, L., Wang, F., Yan, P., Jing, W., Zhang, C., Kudla, J., Zhang, W. (2017): A phosphoinositide-specific phospholipase $\mathrm{C}$ pathway elicits stress-induced $\mathrm{Ca} 2+$ signals and confers salt tolerance to rice. - New Phytologist 214(3): 1172-1187.

[8] Li, Y., Song, Y., Xu, B., Xie, J., Zhang, D., Cooke, J. (2017): Poplar CBF1 functions specifically in an integrated cold regulatory network. - Tree Physiology 37(1): 98-115.

[9] Liu, F., Bai, S. E., Zhang, X. Z. (2017): Design and research of embedded wind power generation monitoring system. - Chinese Journal of Power Sources 41(5): 798-800.

[10] Liu, T., Meng, Q., Han, J. N. (2017): Interference Signal Separation of Computer Communication System Based on Neural Network. - Journal of Jilin University (Science Edition) 55(6): 1545-1551.

[11] Long, T. L., Yi, Y. J. (2014): Progress of the lowering blood lipid effect of medicinal and edible medicine. - Journal of Food Safety \& Quality 41(16): 934-941. 
[12] Lu, K. H., Weng, C. Y., Chen, W. C., Lee, Y. S. (2017): Ginseng essence, a medicinal and edible herbal formulation, ameliorates carbon tetrachloride-induced oxidative stress and liver injury in rats. - Journal of Ginseng Research 41(3): 316-325.

[13] Shang, Q., Yang, G., Wang, Y., Wu, X., Zhao, X., Hao, H., Li, Y., Xie, Z., Zhang, Y., Wang, R. (2016): Illumina-based analysis of the rhizosphere microbial communities associated with healthy and wilted Lanzhou lily (Lilium davidiivar.unicolor) plants grown in the field. - World Journal of Microbiology and Biotechnology 32(6): 95.

[14] Singh, H., Lily, M. K., Dangwal, K. (2015): Evaluation and comparison of polyphenols and bioactivities of wild edible fruits of North-West Himalaya, India. - Asian Pacific Journal of Tropical Disease 5(11): 888-893.

[15] Templ, B., Templ, M., Filzmoser, P., Lehoczky, A., Bakšienè, E., Fleck, S., Gregow, H., Hodzic, S., Kalvane, G., Kubin, E., Palm, V., Romanovskaja, D., Vucetic, V., Žust, A., Czúcz, B., NS-Pheno Team (2017): Phenological patterns of flowering across biogeographical regions of Europe. - International Journal of Biometeorology 61(7): 1347-1358.

[16] Wang, J. M., Ma, S. L., Li, W. Q., Wang, Q., Cao, H. Y., Gu, J. H., Lu, Y. M. (2016): Genetic variability and diversity of the main resources of lily assessed via phenotypic characters, pollen morphology, and ISSR markers. - Genetics and Molecular Research $15(2)$.

[17] Wu, Z., Liang, J., Wang, C., Zhao, X., Zhong, X., Cao, X., Li, G., He, J., Yi, M. (2018): Overexpression of lilyHsfA3s in Arabidopsis confers increased thermotolerance and salt sensitivity via alterations in proline catabolism. - Journal of Experimental Botany 69(8): 2005-2021.

[18] Xu, P. L., Zhu, Z. Q. (2017): Carrier signal injection-based sensorless control for permanent magnet synchronous machine drives with tolerance of signal processing delays. - IET Electric Power Applications 11(6): 1140-1149.

[19] Yu, H. Q., Han, N., Zhang, Y. Y., Tao, Y., Chen, L., Liu, Y. P., Zhou, S. F., Fu, F. L., Li, W. C. (2017): Cloning and characterization of vacuolar $\mathrm{H}+$-pyrophosphatase gene (AnVP1) from Ammopiptanthus nanus and its heterologous expression enhances osmotic tolerance in yeast and Arabidopsis thaliana. - Plant Growth Regulation 81(3): 385-397.

[20] Yu, S., Huang, A., Jia, L., Gao, L., Feng, Y., Pemberton, E., Chen, C. (2018): OsNAC45 plays complex roles by mediating POD activity and the expression of developmentrelated genes under various abiotic stresses in rice root. - Plant Growth Regulation 84(3): 519-531. 